\title{
Smoking cessation treatment for COPD smokers: the role of pharmacological interventions
}

\author{
C.A. Jiménez-Ruiz¹, K.O. Fagerström²
}

\begin{abstract}
Smoking cessation treatment for COPD smokers: the role of pharmacological interventions. C.A. Jiménez-Ruiz, K.O. Fagerström.

Because stopping smoking is such a pressing necessity for COPD smokers physicians should use smoking cessation treatments aggressively. For optimal efficacy smoking cessation in COPD smokers should combine behavioral and pharmacological treatments. Three types of pharmacological treatments are proven to be safe and effective: Nicotine Replacement Therapy (NRT), Bupropion and Varenicline. Use of NRT, bupropion or varenicline,
\end{abstract}

single or in combination, at standard doses or at high doses, for 8-12 weeks or for more than 6-12 months have proven to help these patients to quit. For optimizing efficacy these medications can also be introduced some weeks before actual quitting.

In COPD smoking patients that are not interested in stopping completely or abruptly these medications can be used to aid cessation in a more gradual way.

Pharmacotherapy to aid cessation in COPD smokers have proven to be highly cost effective.

Monaldi Arch Chest Dis 2013; 79: 1, 27-32.

Keywords: Smoking, Pharmacological treatment, Varenicline, Bupropion, Nicotine replacement therapy, High doses of nicotine replacement therapy, COPD smokers.

Fagerström Consulting, Kagerod, Sweden.

1 Unidad Especializada en Tabaquismo, Madrid, Spain.

2 Fagerström Consulting. Kagerod, Sweden.

Correspondence: Unidad Especializada en Tabaquismo, C/ Santa Cruz del Marcenado 9, Madrid 28006; e-mail: victorina@ctv.es

\section{Introduction}

The use of pharmacological treatment for smoking cessation clearly increases the chances to quit smoking. There are several reasons for why it is particularly important that smokers with COPD use pharmacological treatments: first, the high number of cigarettes smoked per day resulting in a high degree of nicotine dependence and second, the urgent need that they have for stopping smoking. Nevertheless, some of these smokers do not want to make a serious attempt to quit. In spite of that doctors must provide them with an adequate treatment tailored to the patient's ambitions that can increase their possibilities of success.

According to different studies there are three types of pharmacological treatments that have proven to be safe and effective for helping smokers with COPD to quit: Nicotine Replacement Therapy (NRT), Bupropion and Varenicline. The description of the pharmacological treatment for smoking cessation in these patients will be explained according to the motivation to quit by these patients.

Pharmacological treatment for smoking cessation in patients with COPD who want to make a serious attempt to stop

The use of NRT, bupropion and varenicline in these patients are strongly recommended.

\section{NICOTINE REPLACEMENT THERAPY}

Most forms of NRT have been studied and proven to be effective for helping these patients to quit smoking.

\section{Efficacy}

Efficacy of nicotine gum in smokers with COPD has been analyzed in several clinical trials [1-4]. The Lung Health Study was a multi-centre, randomized, controlled trial designed to determine whether a program incorporating a smoking cessation intervention and regular use of an inhaled bronchodilator in smokers at high risk of COPD, can slow the annual decline in lung function $\left(\mathrm{FEV}_{1}\right)$. The results showed that, after 12 months, nicotine gum in combination with an intensive behavioral program (patients were seen more than ten times at year, clinic visits lasted about 15 minutes) was significantly more effective in helping smokers at risk for COPD to abstain from smoking than usual care [1]. It should be mentioned that this study made no attempt to compare NRT versus placebo. The efficacy of NRT could be confounded by the fact that the subjects who received NRT also received extensive counseling support.

The second study was conducted by Tonnesen et al in a group of 446 consecutive smokers with mild and moderate COPD. They were randomized 
to receive four types of treatment: nicotine patches, nicotine inhaler, nicotine patches plus nicotine inhaler and placebo. The continuous abstinence rates at 12 months follow up for each arm were as follows: placebo $2 \%$, nicotine inhaler $5 \%$, nicotine patches $9 \%$ and nicotine inhaler plus nicotine patches $6 \%$. There were significant differences between active arms and placebo [2].

Another study was conducted by the same author and it evaluated the efficacy and safety of nicotine sublingual tablets versus placebo with two types of counseling: low and high intensity. The results showed that those who used active treatment had higher continuous abstinence rate at 12 month follow up than those who used placebo: $17 \%$ in the nicotine sublingual tablet and $10 \%$ in the placebo group. There were no differences between high and low intensity counseling [3].

Another study analyzed the effectiveness of continued assistance in smokers with COPD. The aim of this study was to analyze the outcome of a smoking cessation program after one and three years. Abstinence outcomes in a group of COPD patients who participated in a one-year smoking cessation program $(n=247)$ were compared with those of a group of COPD patients who received usual care $(n=231)$. The smoking cessation program included a planned two-week period of hospitalization in a mountain resort. NRT and physical exercise were recommended, and education was given in group sessions. The specially trained staff provided counseling and gave support through phone calls throughout the year. Followups were performed one and three years after the start of the smoking cessation program. In the intervention group: $52 \%$ were smoke free after one year and $38 \%$ after three years. Corresponding quit rates in the control group were $7 \%$ after one year and $10 \%$ after three years [4].

\section{Recommendations for using NRT in COPD smokers}

The following indications should be taken into consideration when NRT is going to be used by these patients.

\section{1. - NRT AT HIGH DOSES}

Adequate replacement percentages are not obtained with the NRT doses generally used. Generally, only between $30 \%$ and $45 \%$ of the levels that a smoker has when smoking are covered. While different studies have demonstrated that the use of nicotine patches at high doses significantly increases efficacy, others have not found this outcome [5-7]. Such treatments seem to be safe and should probably be recommended to COPD smokers. Figure 1 shows some dosing recommendations for full replacement of NRT for smokers smoking 10, 20 and 30 cigarettes /day.

\section{2. - COMBINATION OF DIFFERENT FORMS OF NRT}

The combination of two types of NRT with different types of delivery, one rapid, generally the gum, to achieve a more effective control of crav- ing, and the other, slow, generally the patch, to achieve improvement in the abstinence symptoms is a NRT method that has been tested in several studies [8-10]. It has been demonstrated in all of them that the use of combined therapy is more effective than that of using each one of them separately: (OR 1.9; 95\% CI 1.3- 2.6) [8-11].

Although the limited data available on the combination of NRT plus bupropion has not shown any improved efficacy, the authors clinical experience would not role out that this combination can be tried $[12,13]$.

\section{3. - PROLONGED DURATION OF TREATMENT WITH NRT}

Increasing the time of using NRT could be beneficial for helping smokers to quit. Different studies have proved that increasing the time of using these medications up to 6 or 12 month or even unlimited can help more smokers to quit [14].

\section{4. - COMBINATION OF PHARMACOLOGICAL TREATMENT FOR SMOKING CESSATION WITH TREATMENT FOR DEPRESSION AND OTHER PSYCHIATRIC DISORDERS}

Depression and other psychiatric disorder are frequent among COPD smokers. Most of them smoke as a way of self-medicating to control these diseases. It has been proven that tricycle antidepressants have a positive impact on mood, but side effects limit their use. The adventage of the new antidepressants may improve acceptability and outcomes, but the research is yet to be undertaken. At this moment, few studies have examined pharmacological, psychotherapeutic, or pulmonary rehabilitation treatments for anxiety disorders in the context of COPD. Trials of nortriptyline, buspirone, and sertraline have been found to reduce symptoms of anxiety. Similarly, cognitive-behavioural programs that focus on relaxation and changes in thinking also produced declines in anxious symptoms [15].

\section{BUPROPION}

The mechanism of this drug in smoking cessation is not completely understood. It is known that it

\section{Dosing required for full replacement}

\begin{tabular}{|l|l|l|l|l|l|l|l|l|}
\hline $\begin{array}{l}\# \\
\text { Cigs }\end{array}$ & $\begin{array}{l}\text { Nic } \\
\text { int } \\
\mathrm{mg}\end{array}$ & $\begin{array}{l}\# 2 \\
\mathrm{mg} \\
\text { gum }\end{array}$ & $\begin{array}{l}\# 4 \\
\mathrm{mg} \\
\text { gum }\end{array}$ & $\begin{array}{l}\# 2 \\
\mathrm{mg} \\
\mathrm{loz}\end{array}$ & $\begin{array}{l}\text { mg } \\
\mathrm{mg}\end{array}$ & $\begin{array}{l}21 \\
\mathrm{loz}\end{array}$ & $\begin{array}{l}16 \\
\mathrm{mat} \\
\mathrm{mg} \\
\text { pat }\end{array}$ & $\begin{array}{l}\text { \# In- } \\
\text { hal } \\
\text { puffs }\end{array}$ \\
\hline 10 & 15 & 13 & 5 & 10 & 4 & 1 & 1 & 1500 \\
\hline 20 & 30 & 25 & 10 & 20 & 8 & 1,5 & 1,5 & 3000 \\
\hline 30 & 45 & 39 & 15 & 30 & 12 & 2 & 2 & 4500 \\
\hline
\end{tabular}

Fig. 1. - Recommendations for using NRT at high doses for smokers smoking 10, 20 or 30 cigarettes/day. Total nicotine intake is calculated from $1.5 \mathrm{mg} /$ cigarette. 
acts on the nucleus accumbens where it inhibits neuronal reuptake of dopamine. This effect could explain the reduction in craving experienced by smokers who use bupropion. It also inhibits neuronal reuptake of noradrenaline in the nucleus ceruleus, thus achieving a significant reduction in the intensity of the nicotine withdrawal syndrome [16]. Recent in vitro studies have detected that bupropion is also a non-competitive functional inhibitor of some nicotinic acetylcholine receptors [17].

\section{Efficacy}

There are two studies that analyzed the efficacy and safety of bupropion and nortryptiline in smokers with mild and moderate COPD $[18,19]$. The Taskhin study was carried out among 404 smokers with mild or moderate COPD. It was a randomized controlled trial that evaluated the efficacy and safety of 12 weeks treatment with bupropion vs. placebo. It found that continuous abstinence rate at 6 month follow up was significantly higher for those who used bupropion, $16 \%$ vs. $9 \%$ [18]. There is another randomized placebo controlled clinical trial that evaluated the efficacy and safety of two different treatments: nortryptiline and bupropion. The study was carried out among of a group of 255 smokers with mild or moderate COPD or at risk of developing it. Continuous abstinence rate at 6 month follow up were as follows: $28 \%, 25 \%$ and $15 \%$ for bupropion, nortryptiline and placebo respectively. There was only a significant difference between bupropion and placebo [19].

\section{Recommendations for using bupropion in COPD smokers}

Bupropion should be used for a period of 7 to 12 weeks at a dosage of $300 \mathrm{mg}$ daily taken in two doses of $150 \mathrm{mg}$ each. Treatment should be initiated 7 days before definitively quitting smoking. During the first 3 days or the first week, subjects should only take one $150 \mathrm{mg}$ tablet daily and after this period increase the dose to two $150 \mathrm{mg}$ tablets. The main contraindication for using this drug are as follows: epilepsy, convulsive disorders, bulimia or anorexia nervosa, simultaneous use of IMAO, hepatic cirrhosis and bipolar disorder. Insomnia, mouth dryness, headache, skin allergic manifestations are the most frequent side effects. Seizures only appear in $0.1 \%$ of cases $[20,21]$.

Increasing the time of using bupropion could be beneficial for helping smokers to quit without increasing adverse reactions. With bupropion as with all treatments for smoking cessation prolonged duration beyond the recommended period may be called for in selected patients [22].

\section{VARENICLINE}

Varenicline is a drug specifically developed to aid smokers quit smoking. It acts as a selective partial agonist at the $\alpha 4 \beta 2$ nicotinic receptors in the brain. As it is a partial agonist, it has common characteristics of agonists and antagonists [23, 24].

\section{Efficacy}

A recent study by Taskhin et al studied a group of 505 smokers with mild and moderate COPD. It was a randomized placebo controlled clinical trial designed to evaluate the efficacy and safety of varenicline for 12 weeks plus counseling for smoking cessation. The results showed that continuous abstinence rate between 9 and 52 weeks follow up was significantly higher in the active group, $17 \%$ vs. 6\%; OR: 4.04 (2.13-7.67) $\mathrm{P}<0.001$ [25].

\section{Clinical experience}

The clinical records of all smokers with severe or very severe COPD that have been treated in our Smoking Cessation Service in Madrid from January 2004 to January 2010 have been reviewed. Four hundred and seventy two smokers that had received treatment for smoking cessation were identified. Smokers attended the Smoking Cessation Service referred by their physicians and because they want to make a serious attempt to quit. They received a combination of cognitive behavioral treatment plus pharmacological treatment. Patients received cognitive behavioral treatment during 10 Clinic visits. The schedule of these visits were as follows: baseline visit, $1^{\text {st }}, 2^{\text {nd }}, 4^{\text {th }}, 6^{\text {th }}$, $8^{\text {th }}, 10^{\text {th }}, 12^{\text {th }}, 16^{\text {th }}$ and $24^{\text {th }}$ weeks after quit date. The baseline visit lasted around 20-25 minutes and the rest of the visits around 10-15 minutes. As pharmacological treatment we used: NRT (gum, patches and a combination of patch and gums), bupropion or varenicline, single or in combination. The results showed that $48.5 \%$ of patients were successful at 24 week follow up. When, we analyzed the abstinence rate according to the type of treatment, we found that abstinence rate for those who have used nicotine patches was $44 \%, 55 \%$ for those who have used bupropion and $61 \%$ for those who have used varenicline. When we compared the groups, we found that those who have used varenicline had significantly higher quit rates compared with those who have used nicotine patches: OR: $1.98 ; 95 \% \mathrm{CI}: 1.25-3.12 ; \mathrm{p}=.003$ [26].

\section{Recommendations for using varenicline in COPD smokers}

Different meta-analyses have proven that varenicline is effective and safe at a $1 \mathrm{mg}$ dose twice a day. Varenicline should be used for 12 weeks with tapering up the dose during the first week $(0.5 \mathrm{mg}$ once daily for the first 3 days and then $0.5 \mathrm{mg}$ twice for the next 4 days whereafter the full dose $1 \mathrm{mg}$ twice daily is taken for the remaining 11 weeks) and stopping smoking is recommended on day 8 but can also occur at any time within the first month [27].

One study tested extended use of 12 vs. 24 weeks of varenicline. It was found that an additional 12 weeks of varenicline therapy had a small but significant increase from $36.9 \%$ continuous abstinence with regular use to $43.6 \%$ in 24 weeks use at week 52 [28]. In a secondary analysis of 
these data, it was found that those smokers who had an initial delay in achieving sustained abstinence after the quit-date may be more likely to benefit from extended treatment with varenicline until 24 weeks. In this study it was found that: a) subjects who had their last cigarette at week 11 of open-label treatment had quit rates at 52 weeks of $5.7 \%$ compared with $54.9 \%$ in those who last smoked in week 1 (OR) $20.3(6.3,65.9)$; P < 0.0001], b) patients who failed to initiate abstinence in the first week benefited more from extended treatment than patients continuously abstinent from week 1 (active OR 1.7,1.2, 2.4; $\mathrm{P}=0.001$ versus placebo OR $1.10 .8,1.5 ; \mathrm{P}=0.69$, with the interaction of the quit pattern with treatment effect reaching borderline significance, $\mathrm{P}=0.049$ ) [29].

\section{Pharmacological treatment for smoking cessation in patients with COPD who do not want to make a serious attempt to stop}

Some smokers with COPD are not interested in giving up smoking in spite of knowing that smoking is damaging their health. These patients must also receive counseling of high intensity and must be encouraged by their health physicians to quit as soon as possible. The nicotine dependence of these patients should be addressed at every clinic visit and they should receive advised again smoking for 5 to 10 minutes.

Some studies have shown that the use of pharmacological treatments even in these patients can increase their possibilities to reach abstinence. Two types of pharmacological treatments can be recommended: the use of NRT or varenicline for reducing the number of cigarettes smoked daily as a prelude to a definitely quit.

\section{Using NRT for helping smokers to progressively reduced the number of cigarettes smoked as a gateway to definitely quit}

The gradual reduction smoking cessation method has been proved to be safe and efficacious in smokers who don't want or are unable to quit abruptly. The main objective of this method is to stop smoking gradually. Smokers reduce their number of cigarettes smoked daily and use NRT (mainly nicotine gums) to help and maintain a significant reduction. At the end of the period of reduction smokers should completely stop and continue using NRT [30]. Different randomized clinical trials have seen quitting and significantly more so in active group in smokers who are unmotivated to quit with this less dramatic quitting procedure [31-34]. Unfortunately not all COPD smokers are motivated to quit. Using this approach with them can help them to increase their motivation and to build up their self-efficacy in quitting. In an open follow up study that we carried out with a small number of COPD smokers who were unable to quit, we found that using this approach during 18 months, $50 \%$ of the patients were successful in quitting after using nicotine gum for this time and the remainder halved their smoking [35].

\section{Using varenicline in smokers who do not want to quit}

Varenicline has an antagonist effect and it can block the $\alpha 4 \beta 2$ nicotinic receptors. A placebocontrolled pilot study was conducted in two centres in US with 110 and 108 subjects, respectively. Patients were screened for not having an interest in quitting at the time but were interested to quit at some time in the future. They had to accept to take medication for at least 2 weeks and no longer than 8 weeks, unless they had stopped and needed medication to maintain abstinence. The results of the study showed that Varenicline increased quit attempts significantly over placebo at one site but not at the other. Motivation increase significantly and a non-significant trend towards more successful quitting was observed [36]. Taking into account these results it can be considered that using varenicline in COPD smokers who do not want to quit can increase their possibilities to make a serious attempt to quit and get success in abstinence.

Another interesting study has evaluated if increasing the prequit varenicline period renders cigarettes less satisfying and facilitates quitting [37]. One hundred one smokers attending a stop-smoking clinic were randomly allocated to receive varenicline for 4 weeks before the target quit date (TQD) or to receive placebo for 3 weeks before the TQD, followed by varenicline for 1 week before the TQD. Smokers attended the smoking cessation service by means of advertisement. In both groups, standard varenicline treatment was given for 3 months after the TQD. The results showed that varenicline preloading reduced prequit enjoyment of smoking $(\mathrm{P}=.004)$ and smoke intake $(\mathrm{P}<.001)$, with $36.7 \%$ of participants reducing their cotinine concentrations by more than $50 \%$. Varenicline preloading did not affect postquit withdrawal symptoms, but it increased 12-week abstinence rates (47.2\% in the varenicline arm vs $20.8 \%$ in the placebo arm, $\mathrm{P}=.005)$. The effect was particularly strong among those who reduced their cotinine concentrations by $50 \%$ or more in the varenicline arm, $66.7 \%$ in reducers vs $22.6 \%$ in non reducers, $\mathrm{P}=.002$. Varenicline preloading was well tolerated. Taking these results into account it looks as if presctibing varenicline to non-motivated smokers and using it 4 weeks before quitting in motivated smokers can bring benefits in increasing motivation and successful quitting.

\section{Smoking cessation treatment for smokers with COPD. Results from different meta-analyses}

There are two meta-analyses that have evaluated the efficacy of the different treatments for smoking cessation in COPD smokers. Both have concluded that the combination of pharmacological treatment plus counseling is the most efficacious treatments $[38,39]$.

One of them evaluated the long-term cost and cost- effectiveness of smoking cessation interventions for patients with COPD. A systematic review was performed of randomized controlled trials and 


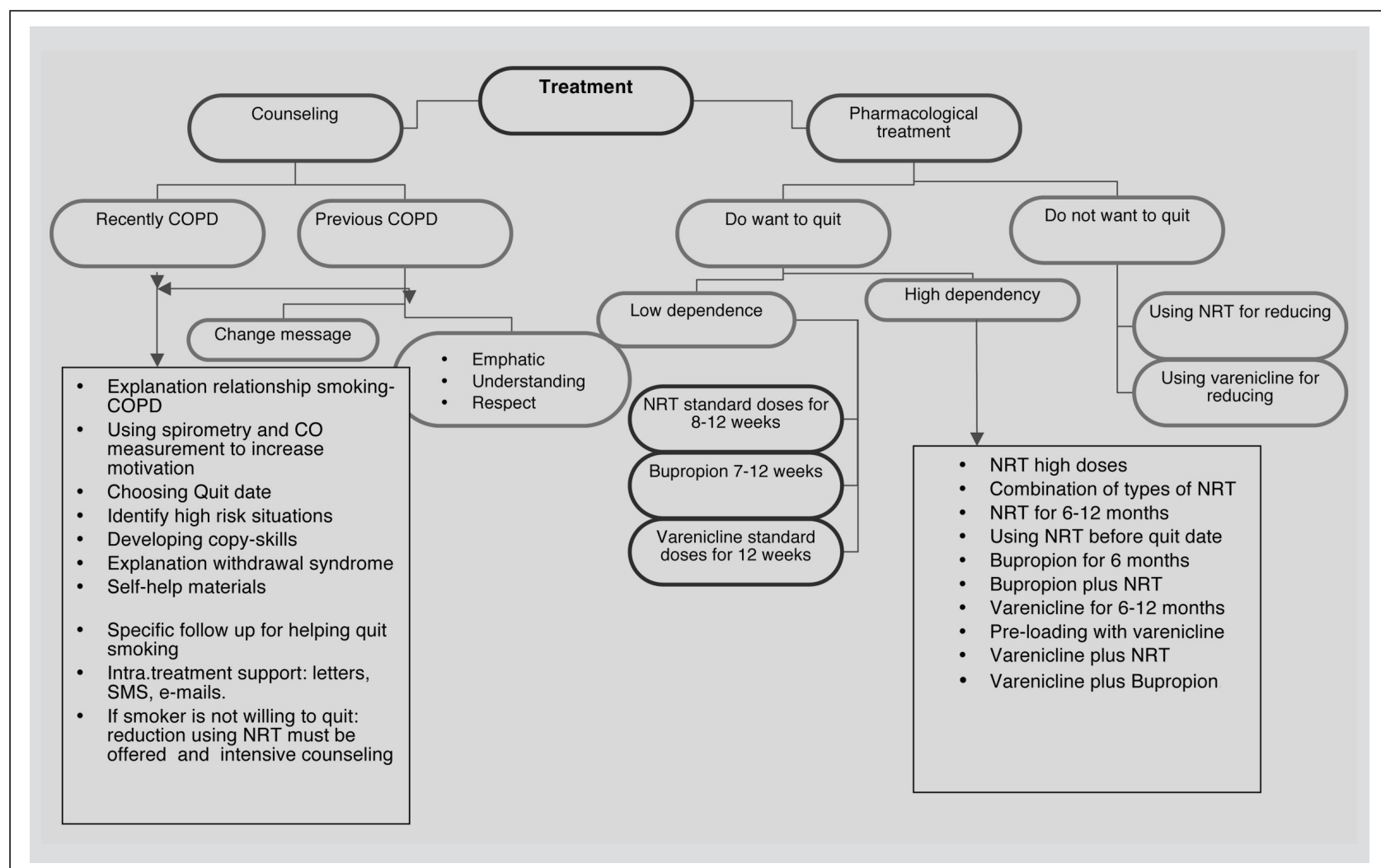

Fig. 2. - Algorithm. Treatment for COPD smokers.

the different interventions were grouped into four categories: usual care, minimal counseling, intensive counseling and intensive counseling + pharmacotherapy ('pharmacotherapy'). For each category the average 12-month continuous abstinence rate and intervention costs were estimated. The results showed that the average 12-month continuous abstinence rates were $1.4 \%$ for usual care, $2.6 \%$ for minimal counseling, $6.0 \%$ for intensive counseling and $12.3 \%$ for pharmacotherapy. Compared with usual care, the costs per quality-adjusted life year gained for minimal counseling, intensive counseling to pharmacotherapy were euro 16 900 , euro 8200 and euro 2400, respectively [38].

The other study analyzed 10 databases to identify randomized trials of smoking cessation counseling (SCC) with or without pharmacotherapy or NRT. Authors conducted a network meta-analysis using logistic regression analyses to assess the comparative effectiveness of smoking cessation interventions while preserving randomization of each trial. The analysis of 7,372 COPD patients from six out of eight identified trials showed that SCC in combination with NRT had the greatest effect on prolonged abstinence rates versus usual care (OR 5.08, p < 0.0001) versus SCC alone $(2.80, p=0.001)$ and versus SCC combined with an antidepressant $(1.53, \mathrm{p}=0.28)$. The second most effective intervention was SCC combined with an antidepressant $(3.32, p=0.002)$ versus SCC alone $(1.83, \mathrm{p}=0.007)$, with no difference between antidepressants. SCC alone was of borderline superiority compared with usual care (1.81, $\mathrm{p}=0.07)$. Authors concluded that a small body of evidence suggests that SCC combined with NRT is more effective than other combinations and single smoking cessation treatments in COPD, but substantially more research is needed for this most important COPD treatment. It is important to take into consideration that this study did not analyze varenicline because of no published data on COPD at the time [39].

In figure 2 there is an algorithm that can aid practitioners in selecting smoking cessation treatments in smokers with COPD [40].

\section{Conclusion}

Stopping smoking is such a pressing necessity for COPD smokers. Physicians should use smoking cessation treatments aggressively. To increase the efficacy of smoking cessation treatments in COPD smokers physicians should combine behavioral and pharmacological treatments. Three types of pharmacological treatments are proven to be safe and effective: Nicotine Replacement Therapy (NRT), Bupropion and Varenicline.

In COPD smoking patients that are not interested in stopping completely or abruptly these medications can be used to aid cessation in a more gradual way.

\section{References}

1. Anthonisen NR, Connett JE, Kiley JP, et al. Effects of smoking intervention and the use of an inhaled anticholinergic bronchodilator on the rate of decline of $\mathrm{FEV}_{1}$ : The Lung Health Study. JAMA 1994; 272: 1497-1505.

2. Tønnesen P, Mikkelsen KL. Routine smoking cessation with 4 nicotine regiments in a lung clinic. Eur Respir J 2000; 16: 714-722.

3. Tønnesen P, Mikkelsen K, Bremann L. Nurse-conducted smoking cessation in patients with COPD, using 
nicotine sublingual tablets and behavioral support. Chest 2006; 130: 334-42.

4. Sundblad BM, Larsson K, Nathell L. High rates of smoking abstinence in COPD patients: smoking cessation by hospitalization. Nicotine Tob Res 2008; 10: 883-90.

5. Tonnessen P, Paoletti P, Gustavsson G, et al. Higher dosage nicotine patches increase one-year smoking cessation rates: results from the European CEASE-trial. Eur Respir J 1999; 13: 238-246.

6. Jorenby DE, Smith SS, Fiore MC, et al. Varying nicotine patch dose and type of smoking cessation counseling. JAMA 1995; 274: 1347-1352.

7. Hughes JR, Lesmes GR, Hatsukami DK, et al. Are higher doses of nicotine replacement more effective for smoking cessation. Nicotine Tob Res 1999; 1: 169-174.

8. Fagerstrom KO, Schneider NG, Lunell E. Effectiveness of nicotine patch and nicotine gum as individual versus combined treatments for tobacco withdrawal symptoms. Psychopharmacology 1993; 111: 271-277.

9. Kornitzer M, Boutsen M, Dramaix M, Thijs JK, Gusstavsson G. Combined use of nicotine patch and gum in smoking cessation: a placebo-controlled clinical trial. Prev Med 1995; 24: 41-47.

10. Puska P, Korhonen H, Vartiainen E. Combined use of nicotine patch and gum compared with gum alone in smoking cessation: a clinical trial in North Karelia. Tob Control 1995; 4: 231-235.

11. Stead LF, Perera R, Bullen C, Mant D, Lancaster T www.cochrane.org/reviews/en/ab000146.html. Access 6 April 2012.

12. Killen JD, Robinson TN, Ammerman S, et al. Randomised clinical trial of the efficacy of bupropion combined with nicotine patch in the treatment of adolescent smokers. J Consult Clin Psychol 2004; 72: 729- 735.

13. Piper ME, Federman EB, McCarthy DE, et al. Efficacy of bupropion alone and in combination with nicotine gum. Nicotine Tob Res 2007; 9: 947-54.

14. Hurt R. Clinical Implications of Long-Term Nicotine Use, in Ferrence R, Slade J, Room R, Pope M (eds). Nicotine and Public Health. Washington, DC: American Public Health Association; 2000: 389-409.

15. Fiore MC, Jaen CR, Baker TB, et al. Treating Tobacco use and dependence: 2008 update. Clinical practice guideline, Rockville MD. US.Deparment of Health and Human Service. May 2008.

16. Lerman C, Shields PG, Wileyto EP, et al. Effects of dopamine transporter and receptor polymorphins on smoking cessation in a bupropion clinical trial. Health Psychol 2003; 22: 541-8.

17. Cryan JF, Bruijnzeel AW, Skjei KL, Markou A. Bupropion enhances brain reward function and reverses the affective and somatic aspects of nicotine withdrawal in the rat. Psychopharmacology (Berl) 2003; 168: 347-358.

18. Tashkin DP, Kanner R, Bailey W, et al. Smoking cessation in patients with chronic obstructive pulmonary disease: a double-blind, placebo-controlled, randomised trial. Lancet 2001; 357: 1571-5.

19. Wagena EJ, Knispchild PG, Huibers MJ, et al. Efficacy of bupropion and nortryptiline for smoking cessation among people at risk for or with COPD. Arch Intern Med 2005; 165: 2286-92.

20. Jarvis M, Powell S, Marsh H. A meta-analysis of clinical studies confirms the effectiveness of bupropion SR in smoking cessation. $7^{\text {th }}$ Annual Conference of the Society for Research of Nicotine and Tobacco. Seattle. Washington. 2001.

21. Hughes JR, Stead LF, Lancaster T. Antidepressants for smoking cessation. The Cochrane database of systematic reviews. 2004 Issue 4 Art No: CD 000031.
22. Hays JT, Hurt RD, Rigotti NA, Niaura R, Gonzales D, Durcam MJ, et al. Bupropion SR for pharmacologic relapse prevention after smoking cessation. A randomised controlled trial. Ann Intern Med 2001; 135: 423-33

23. Tapper A, Knney SL, Nashimi R. Nicotine activation of alpha4 receptors: sufficient for reward, tolerance, and sensitization. Science 2004; 306: 1029-1032.

24. Zierler-Brown SL, Kyle JA. Oral varenicline for smoking cessation. Ann Pharmacother 2007; 41: 95-99.

25. Tashkin DP, Rennard S, Hays JT, et al. Effects of varenicline on smoking cessation in patients with mild to moderate COPD: a randomized controlled trial. Chest 2011; 139: 591-9.

26. Jiménez-Ruiz CA, Ramos Pinedo A, Cicero Guerrero A, et al. Characterisitics of COPD smokers and effectiveness and safety of smoking cessation medications. Nicotine Tob Res 2012; 14: 1035-9. doi: 10.1093/ntr/nts001.

27. Cahill K, Stead LF, Lancaster T. Nicotine receptor partial agonists for smoking cessation. Cochrane Database Syst Rev 2011 Feb 16; (2): CD006103.

28. Tonstad S, Tonnesen P, Hajek P, et al. Effect of maintenance therapy with varenicline on smoking cessation: A randomized controlled trial. JAMA 2006; 296: 64-71.

29. Hajek P, Tønnesen P, Arteaga C, Russ C, Tonstad S. Varenicline in prevention of relapse to smoking: effect of quit pattern on response to extended treatment. $A d$ diction 2009; 104: 1597-602.

30. Fiore MC, Baker TB. Clinical practice. Treating smokers in the health care setting. $N$ Engl J Med 2011; 365: 1222-31.

31. Stead LF, Lancaster T. Interventions to reduce harm from continued tobacco use. Cochrane database System Review 2007; 18 (3) CD 005231.

32. Carpenter MJ, Hughes JR, Solomon LJ, Callas PW. Both smoking reduction with nicotine replacement therapy and motivational advice increase future cessation among smokers unmotivated to quit. $J$ Consult Clin Psychol 2004; 72: 371-381.

33. Batra A, Klinger K, Landfeldt B, Friederich H, Westin A, Danielsson T. Smoking reduction treatment with a $4 \mathrm{mg}$ nicotine gum: a double-blind, randomized, placebo-controlled study. Clin Pharmacol Ther 2005; 78: 689-696.

34. Rennard SI, Glover E, Leischow S, et al. Efficacy of nicotine inhaler in smoking reduction: a double-blind, randomized trial. Nicotine \& Tob Res 2006; 8: 555-564.

35. Jiménez Ruiz CA, Solano S, Alonso Viteri S, Barrueco Ferrero M, Torrecilla M, Hernández Mezquita M. Harm Reduction - A Treatment Approach for Resistant Smokers with Tobacco-Related symptoms. Respiration 2002; 69: 452-455.

36. Hughes J, Rennard S, Fingar J, Talbot SK, Callas PW, Fagerstrom KO. Efficacy of Varenicline to Prompt Quit Attempts in Smokers Not Currently Trying to Quit: A Randomized Placebo-Controlled Trial. Nicotine Tob Res 2011; 13: 955-64. Epub 2011 Jun 7.

37. Hajek P, McRobbie HJ, Myers KE, Stapleton J, Dhanji AR. Use of varenicline for 4 weeks before quitting smoking: decrease in ad lib smoking and increase in smoking cessation rates. Arch Intern Med 2011; 171: 770-7.

38. Hoogendoorn M, Feenstra TL, Hoogenveen RT, Rutten-van Mölken MPMH. Long term effectiveness and costeffectiveness of smoking cessation interventions in patients with COPD. Thorax 2010; 65: 711-8

39. Strassmann R, Bausch B, Spaar A, et al. Smoking cessation interventions in COPD: a network meta-analysis of randomised trials. Eur Respir J 2009; 34: 634-40.

40. Jimenez Ruiz CA, Riesco Miranda JA, et al. Recomendaciones para el tratamiento del tabaquismo en fumadores con EPOC. Arch Bronconeumol In press. 